\section{Aus der Kurve}

\author{
F. Fischer
}

Angestrengt umklammerte seine Hand den kalten Metallgriff. "Ich öffne das Fenster», dachte er, so wie er jetzt alles, was er tat, erst denken musste. Schweiss glänzte auf seiner Stirn. Der Lärm eines unten vorüberfahrenden Lastwagens drängte mit der kalten Nachtluft nach innen. Er liess den Griff los, stand still, den Blick nach unten. Schnell zog er die Luft zwischen den Lippen hindurch, rein und raus, bis ihm schwindelte. Nur nicht aufhören zu atmen, dachte er. Er wollte nicht erstarren, so wie die Welt hier erstarrt war. Solange er atmete, solange er sich bewegte, lebte sie noch. Er musste in Bewegung bleiben. Er lief durch die Zimmer, von einem zum anderen. Schaute aus den Fenstern. Nicht nach hinten, auf den Garten im Hinterhof, sondern nach vorne, auf die Strasse, wo sich in der Tiefe etwas regte, die Lichter der Autos auf- und abpatrouillierten, pausenlos, unter einem schwarzen Himmel, der alles zu ersticken drohte. Der Lichterstrom hatte etwas Beruhigendes, er spürte Ruhe, seltsame Ruhe von der Strasse aufsteigend. Die Bewegung der Welt da draussen, die er sonst scheute, erleichterte ihn.

Auch in ihm lärmte es. Gedanken entfalteten sich, zogen ihre Bahnen, in ihm und um ihn herum, brachen plötzlich auf, verfehlten ihr Ziel. Schlugen Haken, liefen ins Leere, nahmen neuen Anlauf.

Mit der Hand berührte er den Sessel. Sein Lieblingssessel, in dem er immer so herrlich bequem einsank, die Beine hochgelegt - auch das war gefährlich geworden. Fast versunken wäre er in ihm, ohne Boden, gestern, beim Eindunkeln. Noch Stunden später hatte er gezittert, nur schon beim Gedanken an diesen Moment. Er zog seine Hand zurück, schritt weiter, hin und her, von einem Zimmer zum anderen, unentwegt.

Die Uhr schlug. Aber er konnte nicht schlafen, schon seit Tagen nicht mehr. Im Bett liegen, aufsein, essen, nicht essen? Sitzen, stehen, laufen? Sein Blick suchte Halt an den Autos unten auf der Strasse, an ihrer festen Bahn, auf der sie unbeirrbar dahinzogen, Tag und Nacht, ohne Anfang und ohne Ende.

Tanja lag nebenan, er stand an der Türe. Ihre Lider waren geschlossen, regelmässig ging ihr Atem. Auch sie war komisch geworden, fremd, anders, hatte ihn in den letzten Tag so eigen angeschaut, wenn sie dachte, er merke es nicht - aber er merkte es, er merkte viel mehr als früher, nur zeigte er nichts

Korrespondenz:

Frank Fischer

Pfruendhofstrasse 54

CH-8910 Affoltern am AIbis

E-mail: fischerei@dplanet.ch davon. Alles war anders geworden, Zeit und Raum zerfielen, er kannte diese Dinge, hatte selbst oft genug davon erzählt bekommen, wenn er in der Klinik Gespräche führte. Er hatte sich selbst vor Augen, sah sich wie in einem Film, sah sich sprechen, verständnisvoll zuhören, erklären - nur war jetzt er es, der das alles erlebte. Nichtssagend auf einmal alle Erklärungen, die schönen klugen Gedanken, sie rutschten weg von ihm, in eine andere Welt, die Schlüssel passten nicht, seine jedenfalls nicht mehr, bei ihm war es Wirklichkeit, keine Krankheit, nein, es war so wie er es erlebte, so war es.

Noch durfte er ruhig sein. Die Autos durchfuhren die schwarze Nacht.

Am Morgen zog einer die Decke, die Schatten der Nacht lichteten. Dann aber kam der Vogel, schlug deckenschwarz an die Scheibe, torkelte über das Sims, flatterte durch das halbgeöffnete Fenster ins Zimmer. Der Mann erschrak. Auch der Vogel hatte Angst, flatterte, wollte raus, knallte von innen gegen die Scheibe, schwankte, suchte erst unter dem Tisch Zuflucht, dann unter dem Schrank, blieb unruhig, hüpfte hin und her, sass schliesslich still. Jetzt traute er sich, griff nach dem Tier, das sich laut piepsend seinen Fingern entwandt. Er zerrte am Schrank, der Vogel flüchtete unter das Bett, steigerte seine Unruhe. "Flieh" schrie er, immer lauter, immer wieder "fliehflieh", und trug dabei sein Gesicht, schrie, bis auch er schrie, bis Tanja ins Zimmer stürzte, bis sie ihn an sich zog, fest ihre Arme auf ihn legte, ihn nicht mehr losliess. Ihr Herz schlug wie das Vogelherz, er konnte sein eigenes loslassen. So kannte er sie, seine Tanja, das war sie, jetzt konnte er tiefer atmen, sie streichelte ihn. "Du musst in die Klinik, du weisst es", sagte sie, von weit weg, drehend, so wie in den letzten Tagen, ihre seltsamen Blicke, da war es wieder.

Im Aufnahmegespräch schwieg er, klammerte sich an Tanja fest, die viel sprach, weit von ihm weg, selbst wenn sie ihn anschaute, streichelte. Er wollte sie nicht loslassen, war aber bald alleine, im leeren Raum, eine Matratze am Boden, ein Fenster, davor ein Rollo, die Lamellen geöffnet. Draussen stehender Nebel, alte Bäume, kein Leben, keine Autos. Also musste er leben, vom Fenster zur Tür leben, von der Tür zum Fenster, immer weiter leben.

Mit einem schlagenden Geräusch gegen die Tür trat ein Mann ein. Er trug etwas vor sich, hielt es ihm hin, sagte etwas. Er verstand nicht, obwohl ihm die Worte bekannt vorkamen. Die Hand kam nahe, zu nahe. Er schrak zurück, "Was soll das!» schrie es in ihm, doch Beine und Hände blieben, zitterten nur. Der Mann folgte, wieder schrie es in ihm, er hörte den Vogel, "flieh-flieh" schrie er, schlug nach der Hand, es spritzte, es fiel durch die Luft, fiel auf den Boden, verschwand. Er suchte, aber fand nichts. Als er aufschaute, war er allein.

Der junge Mann atmete auf, hielt inne, doch war es nur Ruhe ohne Ruhe, rastlos schritt er hin und her, wollte sich auf die Matratze unter dem Fenster legen, konnte nicht, stand auf, schritt von der Türe zum Fenster, vom Fenster zur Türe. Der Nebel weiss, die Wände weiss. Weisse wortlose Leere, quälende Stille. 
In Bewegung bleiben, nicht nachlassen. Er durfte nicht still stehen. Draussen schrie wieder der Vogel. Er suchte nach ihm, fand nichts. Nur das "Flieh-flieh", unüberhörbar lärmte es. Doch plötzlich wurde es still. Ganz still. Selbst der Vogel verstummte. Draussen vor der Tür Unruhe, halblaute Worte, er verstand nichts, aber es kroch unter dem Holz, kam näher. Menschen brauten sich zusammen. Er fröstelte, es würde kommen, er wusste es. Seit er ein Kind war, wusste er es. Irgendwann werden sie ihn erwischen, so wie damals im Traum, als er flog, ein Vogel mit verschnittenen Flügeln, nur immer so hoch, dass sie ihn gerade verfehlten. Alle Flügelschlag sank er wieder ab, den Atem der Verfolger im Nacken, sprang wieder hoch, lächerliche Meter, die anderen weiter hinter ihm. Er hatte gewusst, dass er träumte, damals, aber es hatte nichts genützt, die Angst blieb die gleiche, der Traum endete nicht, verstrickt blieb er, sank ab, vermeinte schon, die fassenden Hände zu spüren. Damals immerhin gab es Erwachen, einen Ausstieg, ein Auftauchen in das Licht des Bewusstseins, auch wenn der Kampf darunter nie aufhörte, die Hetze nie endete.

Das unklare Zusammengedräue vor der Türe schwoll an, brach ein ins kahle Zimmer, Männer und Frauen drängten hinein, sprachen nicht, schauten zum wankenden Boden, alle bis auf eine, die redete auf ihn ein. Ihre Wörter glitten vorbei und mit ihnen griff jede der Hände nach ihm, drückte ihn auf den Boden, bis er keinen Finger, kein Bein mehr regen konnte. Er spürte den Stich der Spritze, während die
Frau weiter redete und redete. Ein letztes Wort, dann zogen sich die Hände ab, alle auf einmal, mit erleichterten Gesichtern, und verliessen den Raum wortlos, nur der dumpfe Laut der Schuhe, das Rascheln von Stoff, Räuspern. Er blieb zurück, wusste, der Kampf war zu Ende. Er hatte ihn verloren, nach innen sinkend erschlaffte er. Die letzte Hand schloss die Tür.

Still war es. "Flieh-flieh» klang der Vogel, ersterbend, von weit weg. Er hörte ihm nach, bald verstummten die Laute. Er wurde ruhiger, die Lider schwer. Er erhob sich, schwankte, sank wieder auf die Matratze, streckte sich. Er vermisste ein Kissen, bewegte sich, hin und her warf er den Kopf, summte. Zwei Hände legten eine Decke über ihn, zogen ihm die Schuhe aus. Dann liessen sie ihn.

Der vorliegende Text versucht das Abrutschen in eine Psychose zu beschreiben, mit ihren typischen Phänomen bis hin zum psychotisch eingeengten Erleben einer Zwangsmedikation. Eine erste Fassung ist bereits Ende 2000 im Textdiebe-Verlag in München erschienen, in "Textdiebe - Die erste Anthologie» ISBN 3-935376-10-4. In diesem Taschenbuch sind verschiedene Beiträge junger Autoren versammelt, einsehbar auch im Internet unter www.textdiebe.de.

Der Autor steht in der Ausbildung zum Psychiater FMH und schreibt nebenbei Kinderbücher, Theaterstücke, Lyrik und Kurzprosa. 